\title{
A PRODUÇÃO LITERÁRIA CONTEMPORÂNEA NA ESPANHA: CALEIDOSCÓPIO DE SENSAÇÕES, DE ELVIRA CÁMARA AGUILERA - TRADUÇÃO ANOTADA E COMENTADA
}

\author{
CONTEMPORARY LITERARY PRODUCTION IN SPAIN: CALEIDOSCÓPIO DE \\ SENSAÇÕES, BY ELVIRA CÁMARA AGUILERA - AN ANNOTATED AND \\ COMMENTED TRANSLATION
}

\section{PRODUCCIÓN LITERARIA CONTEMPORÁNEA EN ESPAÑA: CALEIDOSCÓPIO DE SENSAÇÕES, DE ELVIRA CÁMARA AGUILERA - TRADUCCIÓN ANOTADA Y COMENTADA}

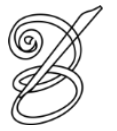 \\ Luciana Ferrari MONTEMEZZO* \\ Universidade Federal de Santa Maria, Brasil
}

\begin{abstract}
Resumo: Este texto tem o objetivo de oferecer ao público brasileiro, ainda que inicialmente, uma nova alternativa de leitura, ao apresentar-lhe uma nova autora. Enfatizando a produção literária espanhola contemporânea, nos debruçamos sobre a recente obra da professora universitária e escritora Elvira Cámara Aguilera (Higuera de Calatrava, Jaén, 1968). Para tanto, traduzimos para o português do Brasil um de seus relatos, publicados na coletânea Memorias de una noche y otros relatos (2015). Com essa iniciativa, nosso objetivo não é apenas dar a conhecer a autora e sua obra, mas também provocar o leitor brasileiro, no melhor sentido da palavra, para que busque conhecer novos autores e, a partir da literatura, seja capaz de estabelecer pontes e diálogos relevantes para o enriquecimento dos dois sistemas literários em questão. Além disso, interessa-nos difundir uma obra que, devido à distância geográfica e aos obstáculos linguísticos, ainda não é conhecida no Brasil. A pesquisa que o processo tradutório levou a cabo fundamentou-se nas premissas de autores como Berman (2004), Carvalhal (2003), Mittmann (2003), Nord (1994) e Vidal Claramonte (2008). Todos estes autores reconhecem, em maior ou menor grau, o papel ativo e decisivo dos tradutores literários e avaliam o processo tradutório como constitutivo no reconhecimento das dessemelhanças entre povos e culturas. De acordo com eles, destacamos o uso de diferentes metodologias para atingir a mesma finalidade: em um determinado caso, ante a impossibilidade de encontrar um equivalente perfeito, optamos por uma solução que implicou perda semântica. Em outro caso, optamos por esclarecer as diferenças por meio de notas de fim, explicitando-as. Durante todo o processo, reivindicamos o espaço da literatura, seja ela vernácula ou estrangeira, como promotora de fruição e imaginação. Estas podem levar a deslocamentos importantes para a compreensão das diferenças entre povos e culturas diversas e que, ao fim e ao cabo, devem colaborar para a cultura de paz.

Palavras-chave: Tradução literária. Literatura Espanhola. Língua Espanhola. Teoria da Tradução. Literatura Comparada.

Abstract: This text of the edition for the Brazilian public, also that opened, a new alternative of reading, for presentation - for a new author. Emphasizing the contemporary Spanish literary production, we focused on the recent work of the university teacher and writer Elvira Cámara Aguilera (Higuera de Calatrava, Jaén, 1968). For that, we translate Brazilian Portuguese from their reports, in the practice of compilation Memorias de una noche y otros relatos (2015). With this initiative, our goal is not only to make the author and her work known, but also to provoke the Brazilian reader, and dialogues relevant to the enrichment of the two literary systems in question, in the best sense of the word, so that it seeks to meet new authors and, from the literature, be able to establish bridges and dialogues relevant to the enrichment of the two literary systems in question. In addition, we are
\end{abstract}


interested in disseminating a work which, owing to geographical distance and language barriers, is not yet known in Brazil. The research that the translation process carried out, was based on of authors as Berman (2004), Carvalhal (2003), Mittmann (2003), Nord (1994) and Vidal Claramonte (2008). All these authors recognize to a greater or lesser extent the active and decisive role of literary translators and evaluate the translation process as constitutive in the recognition of dissimilarities between peoples and cultures. According to them, we highlight the use of different methodologies to achieve the same purpose: in a given case, faced with the impossibility of finding a perfect equivalent, we opted for a solution that implied semantic loss. In another case, we chose to clarify the differences by means of endnotes, making them explicit. Throughout the process, we claim the space of literature, be it vernacular or foreign, as promoter of fruition and imagination. These can lead to important dislocations in order to understand the differences between different peoples and cultures, and which, after all, should contribute to the culture of peace.

Keywords: Literary translation. Spanish Literature. Spanish language. Theory of Translation. Comparative Literature.

Resumen: Este texto tiene el objetivo de ofrecer al público brasileño, aunque de forma inicial, una nueva alternativa de lectura, al presentársele una nueva autora. Poniendo de relieve la producción literaria española contemporánea, nos hemos dedicado a la reciente obra de la profesora universitaria y escritora Elvira Cámara Aguilera (Higuera de Calatrava, Jaén, 1968). Por ello, traducimos al portugués de Brasil uno de los relatos publicados en la coletanea Memorias de una noche y otros relatos (2015). Dicha iniciativa no tiene el solamente objetivo de dar a conocer la autora y su obra, sino también el de provocarle al lector brasileño, en el mejor sentido de la palabra, para que busque conocer nuevos autores y, a partir de la literatura, sea capaz de estabelecer puentes y diálogos relevantes para enriquecer ambos sistemas literarios. Además, nos interesa difundir una obra que, debido a la distancia geográfica y a los obstáculos lingüísticos, todavia no se conoce en Brasil. La investigación del proceso de traducción se ha fundamentado en lo planteado por autores como Berman (2004), Carvalhal (2003), Mittmann (2003), Nord (1994) y Vidal Claramonte (2008). Todos esos autores reconocen, en mayor o menor grado, el rol activo y decisivo que juegan los traductores literarios y evalúan el proceso traductorio como constitutivo en lo que atañe al reconocimiento de las diferencias entre pueblos y culturas. De acuerdo con ellos, destacamos el uso de diferentes metodologías para llegar a la misma finalidad: en un determinado caso, ante la imposibilidad de encontrar el equivalente perfecto, optamos por una solución que conllevó perdida semântica. En otro caso, optamos por aclarar las diferencias por meio de notas de fin, explicitándolas. Durante todo el proceso, reivindicamos el espacio de la literatura, ya sea vernácula o extranjera, como promotora de fruición e imaginación. Éstas pueden llevar a desplazamientos importantes para la comprensión de las diferencias entre pueblos y culturas diversas y que, al fin y al cabo, deben colaborar para la promoción de la cultura de paz.

Palabras-clave: Traducción literaria. Literatura Española. Lengua Española. Teoría de la Traducción. Literatura Comparada.

RECEBIDO EM: 04/06/2019

ACEITO EM: 30/08/2019

PUBLICADO EM: 10/2019 


\section{Introdução}

onheci Elvira Cámara Aguilera (Higuera de Calatrava, Jaén, 1968) no inverno de 2016, em Granada. Além de sermos vizinhas de gabinete na Facultad de Traducción e Interpretación, descobrimos vários interesses em comum. Não apenas a Tradução, como apaixonante objeto de trabalho que é, mas também a escritura criativa. Ante minha curiosidade em conhecer autores espanhóis contemporâneos - sobretudo as mulheres, com as quais o cânone espanhol ainda tem uma dívida -, Elvira apresentou-me nomes como Elena Martín Vivaldi (1907-1998) e, mais do que isso, convidou-me para participar de um grupo coordenado por ela, de mulheres escritoras. Foi então que soube que ela mesma era uma dessas mulheres que eu andava procurando na minha estadia em Granada.

\section{A autora e sua obra}

Além do convite para acompanhar as reuniões do grupo - às quais compareci, com alegria quase infantil, como quem vai a uma festa de aniversário - Elvira mostrou-me seu livro Memorias de una noche y otros relatos (2015). A obra, subdividida por temas, é composta de relatos curtos e, aparentemente, de fácil compreensão, que servem muito bem para aulas de sensibilização à Literatura em Língua Espanhola. Mas sob a aparente facilidade esconde-se uma complexidade quase que filosófica, relacionada com o sentido da existência humana. Se, por um lado, trata de assuntos atuais, com linguagem culta e, ao mesmo tempo acessível, por outro lado, sua prosa em alguns momentos beira o poético e provoca o leitor a avançar em inesperadas interpretações. Além disso, toca por vezes em temas dolorosos, como a situação de adolescentes nos países africanos, ou traições e separações de casais.

De acordo com Rosario Pérez Blanco, escritora madrilenha que apresenta o livro, Elvira é aquela pessoa que, com discrição, de um acontecimento cotidiano, tira uma história. É capaz de transformar uma mera observação ou uma experiência cotidiana em literatura, sem muito alarde. Tanto é assim que aqueles que a cercam correm o risco de se verem retratados vez por outra.

Elvira concilia como poucos sua carreira acadêmica, como professora de Tradução do Inglês e pesquisadora na área Literatura Infantil e Juvenil, na Universidade de Granada. Sua inclinação literária não parece ser afetada pelas obrigações da produção acadêmica. Ao contrário, a disciplina que o ambiente universitário exige parece favorecer sua liderança diante do grupo de escritoras, embora ela mesma não aceite muito confortavelmente a designação de líder. 


\section{Caleidoscopio de sensaciones: o convite para passear por Barcelona}

O relato intitulado Caleidoscopio de sensaciones parece contar a história de uma jovem mulher que chega pela primeira vez ao mercado La Boquería, em Barcelona. Como todo mercado público das grandes cidades, La Boquería atiça todos os sentidos dos seus visitantes. É impossível ficar alheio aos cheiros, sabores e às cores. É difícil não querer tocar e experimentar aquela imensa variedade de mercadorias que se exibem atrativamente aos olhos dos transeuntes.

Tecendo comentários para esta tradução, a autora destacou que a experiência de conhecer La Boquería causou-lhe tantas sensações que precisou registrá-las: “me pareció algo mágico. Los mercados suelen ser sucios, grises, apagados, desordenados... y este es todo lo contrario: luz, color, orden, armonía...". Como boa narradora que é, Elvira transformou um pouquinho de realidade em um belo e sensual relato.

O narrador onisciente em terceira pessoa parece acompanhar a jovem mulher e desfrutar de seu passeio, lentamente: na primeira banca, a maçã do amor traz à tona lembranças da infância, de sabores já experimentados. Na seguinte, o potinho de salada de frutas mistura novos sabores a outros já conhecidos. Ali, a dona da banca arrebata a jovem de suas reminiscências, ao comentar sobre a dificuldade de deixar tudo pronto para os clientes, desde muito cedo. Interrompida quando se preparava para fazer uma foto, a jovem intimida-se e se dá conta do elemento humano que está por trás de cada um daqueles espaços tão encantadores. Depois de um breve diálogo, em que observa as marcas do tempo nas mãos de sua interlocutora, segue o passeio. Passa pela banca de peixes, onde o cheiro de mar traz novamente lembranças de sua infância. Em seguida, avança em direção a uma banca de objetos de decoração e doces natalinos. Embora não seja época de Natal, há ali uma variedade de mercadorias que, uma vez mais, provocam seus sentidos. Sente-se estranha, sem saber explicar por que aquela banca a atrai especialmente. Desta vez, a atende um homem, que lhe oferece uma degustação de doces e bebidas. Ela tenta evadir-se, alegando que já não tem mãos para carregar suas compras. $\mathrm{O}$ vendedor, então, dispõe-se a entregar o que ela queira comprar, quando o mercado fechar. Um pouco indecisa, acaba por dar o endereço de onde está hospedada. A voz narrativa avisa ao leitor das intenções do vendedor: "la había estado observando. La había seguido de puesto en puesto con interés [...] y se había dicho que si se acercaba no la dejaría escapar" (CÁMARA AGUILERA, 2015, p. 100). A partir de então, o leitor passa a participar, também, de um movimento de sedução que avança pelas ruas centrais de Barcelona, ao cair da noite. A encantadora cidade acaba por participar daquela aventura regada a uma boa cava espanhola, 
presente do dono da banca à cliente. $\mathrm{O}$ final cumpre com as expectativas iniciais do relato e o encerra com harmonia.

Como dissemos anteriormente, a narrativa parece contar a história de uma jovem que vai ao mercado. Mas também poderíamos afirmar que o protagonista deste relato é o próprio mercado, com suas múltiplas identidades, com sua diversidade, cores e sabores. O passeio da jovem, a atração pelos produtos e depois pelo vendedor podem ser analisados como ponto de partida para destacar um dos lugares mais emblemáticos da capital catalã. Um espaço onde podem ser vistos desde curiosos turistas até cidadãos comuns, que estão ali para fazer a feira do dia. Todos interagindo entre si, capitaneados pelos vendedores, que comandam o espetáculo.

\section{A tradução: discussão das principais dificuldades}

O processo tradutório contou com a participação da autora, também tradutora. Embora não conheça a fundo a Língua Portuguesa, sua vasta experiência na área foi fundamental para as decisões encontradas. A linguagem aparentemente simples, como era de prever, escondia algumas dificuldades, provocando movimentos em nível de subtexto, que o processo tradutório revelou. Tal movimento é muito bem sintetizado por Berman (2002, p. 20): "todo texto a ser traduzido apresenta uma sistematicidade própria que o movimento de tradução encontra, enfrenta e revela". O apelo sensorial característico da narrativa provocou algumas dificuldades, sobretudo de ordem semântica e ligadas ao estabelecimento de equivalências, como no exemplo a seguir:

Quadro 1 - Exemplo de equivalências

\begin{tabular}{|l|l|}
\hline Texto Fonte & Texto Meta \\
\hline "Los productos parecen haber adquirido & "Os produtos parecem ter adquirido \\
formas geométricas y, casi con rigor & $\begin{array}{l}\text { formas geométricas e, quase com rigor } \\
\text { castrense, una meticulosa imagen de orden }\end{array}$ \\
y armonía se despliega ante los ojos de la & $\begin{array}{l}\text { ordem e harmonia se descortina aos olhos } \\
\text { visitante" (p. 96). }\end{array}$ \\
da visitante".
\end{tabular}

No fragmento anterior, identificamos a existência de um campo semântico que remete à ordem com que estão dispostos os produtos. Assim, "rigor castrense" relaciona-se com o verbo "desplegarse", verbo este de difícil tradução para o português brasileiro. De acordo com o Diccionario de la Real Academia Española (online), “desplegarse” significa: 
1. Desdoblar o extender lo que está plegado.

2. Aclarar o hacer patente lo que estaba oscuro o poco inteligible.

3. Ejercitar o poner en práctica una actividad, o manifestarse una cualidad.

4. Hacer pasar las tropas o los buques del orden cerrad al abierto y extendido.

Assim sendo, a acepção que corresponde ao uso em espanhol é a primeira, "desdoblar o extender lo que está plegado". Sob tal ponto de vista, "descortinar-se" evidenciou-se como uma solução adequada, uma vez que dá a ideia de abertura e de exposição, inerentes às atividades do mercado. Entretanto, seu uso não está relacionado semanticamente a "rigor castrense", como seria desejável. Diante da impossibilidade de equivalência absoluta, restounos a resignação, reforçada pela memória dos ensinamentos de Nord (1994, p. 97), que reflete sobre a falta de univocidade para a definição do termo "equivalência" e afirma que há "[...] 58 nociones diferentes de equivalencia solo en literatura traductológica escrita en alemán [...]”.

Os avanços dos estudos tradutológicos, a partir da virada do século XXI, demonstraram que não apenas o conceito - instável de per si-de equivalência precisaria ser revisto. Puseram em evidência também aqueles aparentemente mais estáveis, como fidelidade e original, que 212 precisaram ser modalizados. Em lugar de fidelidade, optamos por discutir ética profissional e lealdade ante os destinatários das traduções: editoras e leitores em especial. Ser fiel, atualmente, não significa traduzir palavra por palavra - para isso temos os programas de tradução - nem muito menos manter a estrita ordem sintática da frase. Significa, isto sim, garantir integralidade textual, respeitando todos os entes da cadeia comunicativa que o processo tradutório implica, ainda que, para tanto, sejam necessários ajustes de várias ordens.

Há que se dar especial atenção à categoria dos leitores, uma vez que esta é composta por públicos específicos. Sabemos desde o início, que o público-alvo da tradução determina as metodologias empregadas ao longo do processo tradutório. Traduzir para crianças não é o mesmo que fazê-lo para adultos, por exemplo. Portanto, as escolhas e soluções precisam levar em conta esta importante variável.

Assim como os conceitos de equivalência e fidelidade, também houve uma revisão do conceito de original como aquele texto que é irrepetível: passamos a considerar especialmente seu aspecto cronológico: trata-se do texto que nasce antes e que, por conseguinte, origina novos textos - suas traduções.

Este olhar revisionista passou, aos poucos, a ser aceito e naturalizado entre tradutores profissionais, docentes e pesquisadores da área. Mais do que isso, trouxe grande alívio para uma atividade que era, até então, considerada subalterna na área de Letras. O anedótico 
provérbio italiano "traduttore, traditore", por exemplo, até meados dos anos 1990 poderia ser interpretado como uma ameaça, afinal, ninguém em sã consciência estuda anos a fio para, depois, ser chamado de traidor. Libertar-se deste tipo de estigma certamente trouxe para a categoria profissional muito mais fôlego e ânimo diante dos novos desafios que o mundo tecnológico e conectado exige. Sobre o processo de revisão, e a reversão das expectativas, a partir do século XXI, reflete Vidal Claramonte (2008, p. 82-83):

\begin{abstract}
as teorias da tradução do século XXI não discutem a equivalência nem a atribuição de um critério absoluto como prioridade para alcançar um bom texto [...]. A tradução não representa um fenômeno puramente linguístico, mas sim uma realidade, uma necessidade, que participa das identidades culturais, na qual também as instituições políticas e sociais que representam os povos têm muito a dizer, certamente. A tradução não é entendida, pois, como um mero trabalho intelectual, mas como um problema ético [...]. A tradução no século XXI é uma condição permanente do ser humano que se reflete em uma prática discursiva que revela os múltiplos signos da polivalência com as que as culturas estão construídas (VIDAL CLARAMONTE, 2008, p. 82-83, tradução nossa) ${ }^{1}$.
\end{abstract}

De volta à análise do processo tradutório, destacamos que além do exemplo discutido anteriormente, surgiram outras dificuldades, que dizem respeito à culinária espanhola: os doces e guloseimas, em quatro casos específicos que não encontram equivalentes no Brasil. Dois deles são característicos do período natalino na Espanha. A pesquisa incluiu, além de consulta a fontes tradicionais, também uma pequena peregrinação in loco por padarias e confeitarias da cidade de Granada. Infelizmente, como esta etapa da pesquisa aconteceu em abril, os doces natalinos não foram encontrados.

Como se sabe, a culinária é uma manifestação cultural das mais peculiares e, portanto, também de mais difícil tradução. Não apenas porque está relacionada a gostos e diversidade cultural, mas também porque depende da produção de insumos primários que, por sua vez, estão ligados à produção agrícola, às condições climáticas, do solo e à geografia. Por isso, alguns produtos, abundantes em um determinado país podem ser desconhecidos ou escassos em outro.

Neste momento da pesquisa, contamos com a colaboração ativa da autora, que procurou explicar cada um dos doces que não fazem parte da cultura brasileira. Novamente, esbarramos na impossibilidade de encontrar equivalentes. No entanto, desta vez, a metodologia empregada para traduzir foi outra: como se trata de algo muito específico da cultura espanhola, optamos por elaborar notas de fim, com vistas a esclarecer o leitor e, por conseguinte, talvez, provocar sua curiosidade e o seu desejo de experimentar novos sabores. 
A partir da explicitação das diferenças, demonstramos o papel ativo e consciente que cabe ao tradutor na contemporaneidade, negando o apagamento de sua voz. A partir desta metodologia, o tradutor estabelece um relevante lugar de diálogo com o leitor, que transcende a mera perspectiva de utilização do espaço de notas para justificativa de escolhas tradutórias (MITTMANN, 2003).

\section{Considerações finais}

Carvalhal (2003), ferrenha defensora da importância dos Estudos de Tradução para o aprofundamento dos diálogos entre sistemas literários diversos, afirmava que o tradutor é o primeiro crítico de um escritor estrangeiro. É por meio dele - e de sua leitura - que novos leitores conhecerão um novo autor, que escreve em uma língua diferente, mas que, nem por isso, pode, deve ou precisa ser ignorado. Ao contrário, o movimento tradutório, segundo a eminente comparatista, é de fundamental importância para que as sociedades avancem.

Como ela, acreditamos que a literatura é uma porta aberta para novas experiências, um convite à imaginação e à fruição. E que narrativas como Caleidoscópio de sensações podem 214 colaborar para atiçar a curiosidade dos leitores e provocar deslocamentos, sejam eles territoriais ou imaginários. Diante disso, esperamos que a tradução que ora se apresenta seja um convite para que o leitor brasileiro conheça uma pequena parte da produção literária de Elvira Cámara Aguilera. E que este possa ser o começo de um novo diálogo entre dois sistemas literários que têm muito em comum. Boa leitura! 


\title{
CALEIDOSCÓPIO DE SENSAÇÕES
}

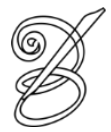 \\ Elvira Cámara Aguilera - Espanha
}

$\mathrm{U}$ $\mathrm{m}$ arrepio percorre seu corpo. Isso somente acontece quando ela tem medo ou se sente ameaçada, nunca quando seus sentidos lutam para ser protagonistas, todos ao mesmo tempo. Pisca os olhos mais rápido que o habitual e se detém para comtemplar o maravilhoso espetáculo. Pega a câmera e faz fotos com insistência desmedida. Suas emoções adquirem forma de sorriso; depois, um sussurro de palavras.

- Que bancas! Que ordem! Que irrupção de cores!

Embora não seja mais do que um mercado público, ela reage como se nunca tivesse visto algo parecido. As bancas se encontram perfeitamente organizadas. Os produtos parecem ter adquirido formas geométricas e, quase com rigor castrense, uma meticulosa imagem de ordem e harmonia se descortina aos olhos da visitante.

A primeira é uma banca de guloseimas. Colocadas como que magicamente em construções simétricas, mais fazem lembrar castelos de carta do que amontoados ordinários de sonhos pueris. Cores e texturas projetam-se com intensidade sob as luminárias: alcaçuz vermelho e também preto, nuvens tão esponjosas como o algodão com o qual, quando era pequena, curavam-lhe os machucados, jujubas ao gosto de escultor infantil, etéreos algodões de açúcar, pirulitos de espirais vertiginosos e maçãs do amor. Nunca mais tinha experimentado uma, desde que tinha nove anos. Agora a lembrança flui.

- Me dá uma maçã, por favor? - pede, enquanto tira o dinheiro de sua bolsa.

Como se quisesse despedir-se dela, olha-a por todos os lados antes de aproximá-la da boca.

- Hummmmm, que delícia!!!!!! Quantas lembranças! - diz, fechando os olhos e deleitando-se com aquele prazer ao alcance de muito poucos.

Entra no mercado da Boquería, mas parece não avançar. Detém-se em cada banca. Agora para no de frutas exóticas.

- Que cores...! E que formas! Tudo está meticulosamente colocado. Muitas das frutas estão organizadas em rigorosas pirâmides: mamões, morangos, kiwis, mangas, abacates, 
framboesas, amoras, abacaxis, cerejas... Sua boca parece acolher os inconfundíveis sabores ao se encher com cada nome. Volta a colocar a mão na bolsa, tira umas moedas e prepara a câmera.

- Um potinho de salada de fruta, por favor.

A embalagem é como um cofre que contém um tesouro, onde foi guardada uma mostra de todas as cores e sabores daquele singular mercado. As cores que, quando era menina, sempre quis reter e alguns sabores que, também quando era menina, nunca conseguiu provar. Agora os tem aí, em suas mãos e em sua boca. Ela, que mantém um ensimesmado monólogo ante o caleidoscópio de sensações, reage e devolve a atenção à senhora da banca que parece tê-la escutado.

- Essas fotos, senhorita, nunca poderão recuperar o sacrifício de tanto trabalho. Sabe quantas horas são necessárias para preparar uma banca assim, tão agradável à vista?

- Puxa... não, não sei... - a interferência da vendedora no seu monólogo lhe pegou de surpresa.

- Eu vou lhe dizer: quatro. Quatro horas, senhorita. E, com sorte, desmontar seria mais rápido. Isso significaria que as vendas foram boas.

216 Agora não sabe se faz a foto. Algo a incomoda. De novo, a vendedora parece ler seus pensamentos e a anima.

- Faça a foto, pode fazer. Mas leve também a lembrança de tanto esforço. Quer que eu tire uma sua ao lado da banca?

- Não, não, não precisa. Prefiro fazer uma foto da senhora, se não se importa.

Depois de escutar a mulher que gerencia a banca, essa mulher com o rosto marcado por rugas, apesar de sua idade, deseja tirar uma instantânea diferente. Quer que sua câmera capte o olhar límpido de quem sabe vender magia para os sentidos e oferecer pequenas doses de uma realidade excessivamente resplandecente para visitantes como ela. Quer fotografar seu cabelo que aspira ser escuro, mas que, por esse excesso da vida, teima em ser branco. Também quer captar suas mãos, repletas de calosidades e cortadas pelo intenso frio das madrugadas; mãos que não parecem aptas para carícias, mas que, algum dia, sem dúvida, devem ter sido leves como plumas sobre uma pele ardente.

Agora se distancia da banca de frutas e se aproxima da de peixe. Sua forma semicircular e sua localização no centro do mercado fazem lembrar um relógio de sol, a luz branca que intensifica o brilho das escamas parece irradiar-se por todas as partes. O cheiro do mar a transporta de novo à sua infância, quando seus pés pisaram pela primeira vez na areia da praia. 
Apenas mantém essa lembrança em sua retina. Está hospedada num hotel no bairro gótico e estará somente três dias na cidade.

Ainda falta algum tempo para o Natal, mas acaba de encontrar uma banca especializada nessas datas. Já enfeitada com festões e guirlandas coloridos, exibe torrões e marzipãs, amanteigados, polvorones ${ }^{2}$, amêndoas, carapinhadas, pinhões, peladillas ${ }^{3}$, deseadas ${ }^{4} . . \mathrm{A}$ interminável lista de vinhos e licores para acompanhar os doces natalinos captam de novo seu pueril interesse. Sente-se estranha. Desconhece o motivo pelo qual aquela banca a atrai especialmente. Aproxima-se e o dono, um homem de meia idade, atlético e aspecto bem cuidado, oferece-lhe uma bandeja com pequenas amostras de seus produtos. Começa a degustar. Um pedacinho de yema ${ }^{5}$ coberto de chocolate com um pouco de vinho doce a fazem decidir. Mas há um inconveniente: já fez muitas compras e não pode mais carregar peso.

- Diga-me o endereço da sua casa que, quando fechar a banca, eu mesmo entrego.

- Estou de passagem.

- Diga-me em que hotel está hospedada, então. - insiste.

Ela titubeia, mas ele mantém o olhar firme nela, que não sabe como evadir-se. Seus lábios, mais rápidos que sua mente, deixam escapar um nome.

- A que horas fica bom para a senhora?

- De tarde, se não é muito incômodo.

- Não é incômodo. O mercado abre apenas de manhã.

Despediram-se. Ele, com um sorriso contido. Ela, com uma sombra de dúvida.

Tinha estado observando-a, seguindo-a de banca em banca com interesse. Era seguro de si mesmo e tinha decidido que, se se aproximasse, não a deixaria escapar. Ela se aproximou, mas não soube que tinha sido ele quem estava determinado a vê-la novamente. E as horas passaram mais lentas do que ele gostaria.

Encontraram-se na recepção do hotel; ele trouxe seu pedido, ao qual acrescentou uma garrafa de cava de excelente qualidade e marca desconhecida para ela. Não quis que pagasse. Não tinha pensado cobrar. Agradecida, ela o convidou para uma cerveja no bar do hotel. Beberam e conversaram e ele ofereceu-se para mostrar-lhe alguns lugares de Barcelona. Ela não soube ou não quis dizer não. Passearam pela cidade e jantaram em um pequeno restaurante (que havia a umas quadras dali). Falaram de Barcelona e também de Madrid; falaram de seus trabalhos e distrações, mas nenhum dos dois quis conhecer muito mais do outro.

No hotel, esperava-lhes uma cálida noite e uma garrafa de cava gelada. 


\section{REFERÊNCIAS BIBLIOGRÁFICAS}

BERMAN, Antoine. A prova do estrangeiro: cultura e tradução na Alemanha romântica. Bauru: EDUSC, 2002.

CÁMARA AGUILERA, Elvira. Memorias de una noche y otros relatos. Madrid: Lastura, 2015.

CARVALHAL, Tania Franco. O próprio e o alheio. São Leopoldo, Ed. Unisinos, 2003. MITTMANN, Solange. Notas do tradutor e processo tradutório. Porto Alegre: Ed. UFRGS, 2003.

NORD, Christiane. Traduciendo funciones. In: HURTADO ALBIR, Amparo. (ed.). Estudios sobre la traducción. Castelló: Publicacions de la Universitat Jaume I, 1994. p. 97-112.

VIDAL CLARAMONTE, María del Carmen África. Traducir en el siglo XXI: nuevos retos. In: GÓMEZ MONTERO, Javier. (ed.). Nuevas pautas de traducción literaria. Madrid: Visor Libros, 2008. p. 75-86.

\footnotetext{
* Luciana Ferrari MONTEMEZZO - Doutora em Teoria e História Literária (2008) pela Universidade Estadual de Campinas. Mestre em Letras (1999) pela Universidade Federal de Santa Maria. Graduada em Letras (1995) pela Universidade Federal do Rio Grande do Sul. Realizou pesquisa de pós-doutorado na Universidad de Granada, Espanha. Professora da Universidade Federal de Santa Maria. Santa Maria, Rio Grande do Sul, Brasil.
}

Currículo acadêmico: http://lattes.cnpq.br/4901993158818284

ORCID: https://orcid.org/0000-0002-4632-5543

E-mail: 1ucesfm@gmail.com

${ }^{1}$ Las teorías de la traducción del siglo XXI no se plantean como prioridad la equivalencia ni la consecución de un criterio absoluto para alcanzar un buen texto [...]. La traducción no representa un fenómeno puramente lingüístico sino una realidad, una necesidad, que participa de las identidades culturales, en la cual también tienen mucho por decir, por supuesto, las instituciones políticas y sociales que representan a los pueblos. La traducción no se entiende, pues, como un mero trabajo intelectual sino como un problema ético [...]. La traducción en el siglo XXI es una condición permanente del ser humano que se refleja en una práctica discursiva que revela los múltiples signos de la polivalencia con las que están construídas las culturas.

${ }^{2}$ Biscoito típico da Andaluzia, feito de farinha, açúcar, leite e nozes e que se despedaça (se hace polvo) quando mordido. Muito apreciado no período nas festas natalinas, é popular em todo o país.

${ }^{3}$ Doce típico da região da Comunidade Valenciana, mas também popularizado por todo o território espanhol, feito de amêndoa confeitada de várias cores. É servido em festas como batizados e casamentos, além do Natal.

${ }^{4}$ Biscoito amanteigado produzido em conventos, também típico da época natalina. Feito de farinha e amêndoas, quadrado e pequeno

${ }^{5}$ Iguaria igualmente originada nos conventos, para aproveitar as gemas dos ovos, uma vez que as claras eram usadas para engomar os hábitos das freiras. Composto basicamente de gema e calda de açúcar, pode ser recoberto com outros ingredientes, como, neste exemplo, o chocolate. 